\title{
Calculation of electrical loads for decentralized power supply systems and the choice of power gas piston installations which use electrochemical energy storage
}

\author{
$A$ Fedotov, $R$ Misbakhov, $N$ Chernova, $K$ Bakhteev and $A$ Akhmetshin \\ Engineering center, Computer modeling, and engineering in the field of power engineering and power engineering Kazan State Power \\ Engineering University, Krasnoselskaja, 51, Russia
}

\begin{abstract}
In autonomous electric power supply systems of remote areas of the country where there are no centralized electric power supply, diesel generator units (DGU), and gas piston installations (GPI) is used as a source of electrical power. Selection of their nominal power determined load value, for which the preliminary calculation using the standard values. Researches of electric power profiles for apartment and public buildings of the Republic of Tatarstan showed a significant difference from the current regulatory values. At present, the regions are granted the right to independently set specific loads for such objects. The article proposes a method for selecting the power of autonomous power plants for actual loads for urban and rural settlements.
\end{abstract}

\section{Introduction and relevance of the study}

The Russian Federation is the largest state in the world in terms of the area of decentralized power supply zones, in which consumers supply power independently, i.e. when electricity is generated exclusively by internal sources. Usually, they are DGU and GPI [1-4]. Such territories include the Far East, the Arctic zone, areas of the Far North, where economic activity is carried out. For the long-term living of staff creates rural settlements. However, apart from them, settlements are developing on a permanent basis. They require the creation of an appropriate infrastructure, which includes children's and school educational institutions, medical institutions. And first of all, a housing fund is created, which includes both individual houses (cottages) and apartment buildings up to 5 floors inclusive. In some cases, higher buildings may occur.

The power supply systems of urban-type facilities are designed on the basis of the values of design loads given in [5]. The fact that they differ significantly from the actual ones can be seen in Figure 1. Substations with a load factor of transformers $\mathrm{kz}$ less than $30 \%$ of their nominal electric power account for $70 \%$ or more of their total. This circumstance is explained by the outdated values of standards [5], which do not take into account the impact of energy-saving technologies on household and office equipment. As a result of the use of these standards, the excess electric power is set in advance in the power installations supplying the power supply systems for housing objects.

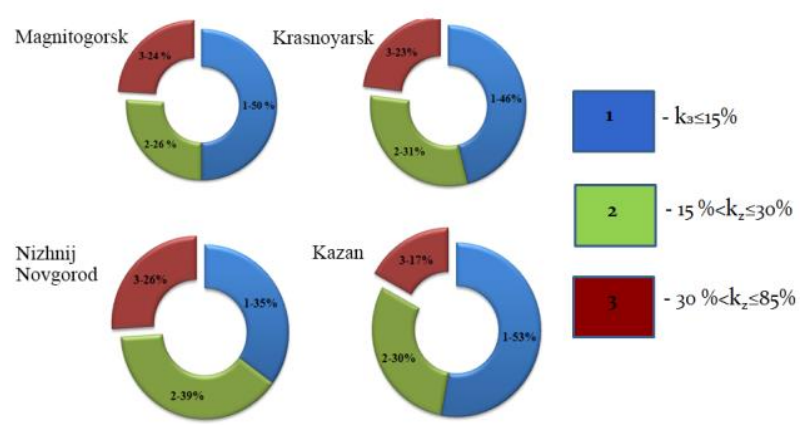

Fig. 1. Upload diagram of transformer substations $0,4 / 10 \mathrm{kV}$.

In the Republic of Tatarstan, over the past few years, specialists of the Association "Roselectromontazh" were carried out on the basis of information provided by OJSC "Grid Company", Kazan, a great job of verifying the loads of apartment and public buildings, which showed significant differences from [5] towards their reduction, which is shown in Table 1 , where the first group includes apartment buildings without elevator up to 5 floors, the second group includes apartment buildings with elevators 6 to 10 floors, both groups have gas-stove.

Regional specifics of the nature of the loads are viewed in Figures 2 and 3. The smaller specific power consumption in Magnitogorsk compared to Kazan, Figure 2, is explained by lower specific loads, Figure 3. At the same time, the nature of the load qualitatively coincides between the two cities. This gives grounds for the dissemination of the results of studies of specific loads of one region on other regions, adjusted for the amount of electrical consumption. 
Table 1. The specific rated electrical load of apartment buildings.

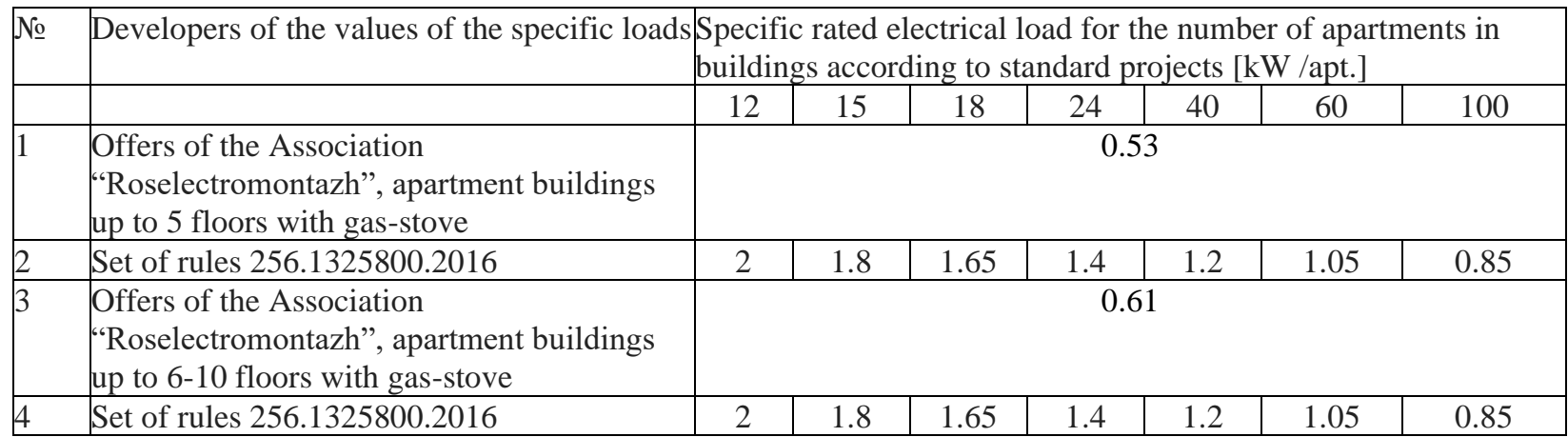

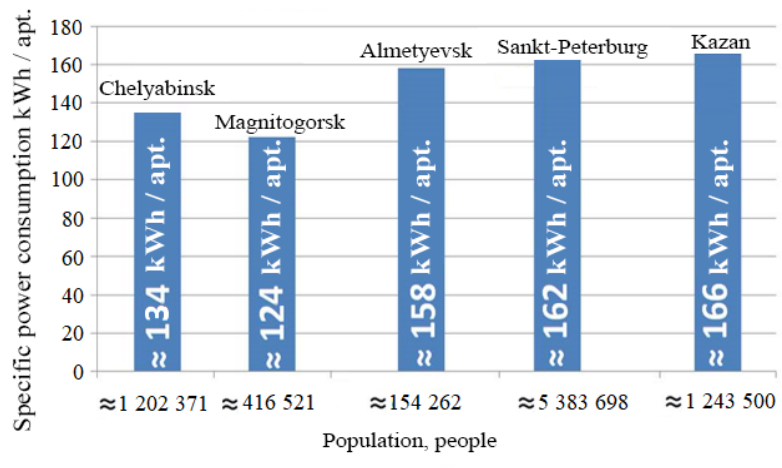

Fig. 2. Specific power consumption in apartment buildings.

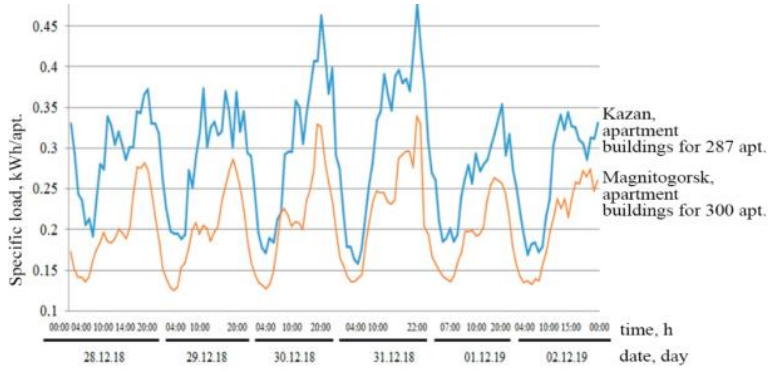

Fig. 3. Daily power graphs for two cities.

Its value is readily available, in contrast to electric power profiles, which can be used selectively to evaluate new specific electric power values introduced in the region.

\section{Experimental research}

For the correct choice of power installation, you must use daily load patterns. Figures 4 show daily power profiles for two cottages in different villages. Figures 5 show daily power profiles of different groups of cottages in the same village. The overall increase in the load of the rural settlement and the effect of the electric boilers on increasing the minimum load pays attention. Observed jumps and load drops of individual cottages are averaged when they are jointly consumed from a single source.

Figures 6 shows the results of the summation of daily power profiles for two rural settlements. The presence of electric boilers significantly narrowed the range of daily power variations - up to $12.6 \%$. While for a village with gas heating, the maximum power is 2.28 times the minimum.

The graphs in Figure 6 also show that local dump and rise of load are smoothed out when summing up, and one can practically disregard the factor of their effect on GPI, which are extremely sensitive to rapid load changes. For the settlement «a» the average load is equal to $\mathrm{P}_{\mathrm{m}}=79.4$ $\mathrm{kW}$, for the settlement «b» $\mathrm{P}_{\mathrm{m}}=373 \mathrm{~kW}$. Analysis of loads of several cottage villages has shown that it is possible to single out the main (first) group of cottages, comprising $85 \%$ of their total number, for which the loads obey the law of normal distribution. For them, in the range, $\mathrm{Pm} \pm 1.64 \sigma$ will be with the probability of 0.9 values of all loads. As a result, we have for rural settlements - $7.5 \mathrm{~kW} \mathrm{/} \mathrm{cottage.} \mathrm{This} \mathrm{value} \mathrm{is}$ recommended to use when the number of objects more than 10 . The second group (15\%) are cottages with a high load, which is random in nature. With a probability of $95 \%$ of the surveyed more than 250 houses, it can be assumed that the maximum load does not exceed $25 \mathrm{~kW}$.

Figure 7 shows, as an example, a combined chart of daily power graphs for three apartment buildings (AB) and three kindergartens $(\mathrm{KG})$.

The graphs of Figure 7 show that the maximum loads of the apartment buildings and pre-school educational institutions are shifted in time: the maximum load of the pre-school educational institutions accounts for daytime, while for the apartment buildings it is the evening time. The maximum load of school educational institutions falls on the morning hours, Figure $8 \mathrm{a}$, which further smooths the total load pattern.

Load patterns of shops and catering enterprises do not have pronounced short-term highs and dips, Figure $8 b$.

Taking the baseload graphs of apartment buildings, we can write the following formula for calculating the maximum total capacity of a residential community (1):

$$
\begin{aligned}
& P_{\max }=P_{\mathrm{u} 1} N_{\mathrm{ap} 1}+P_{\mathrm{u} 2} N_{\mathrm{ap} 2}+k_{\mathrm{m}} N_{\mathrm{c}}\left(0.85 P_{\mathrm{c} 1}+\right. \\
& \left.+0.15 P_{\mathrm{c} 2}\right) P_{G S}+P_{C f}+k_{\mathrm{Kg}} P_{S \mathrm{c}}+k_{\mathrm{Sc}} P_{S \mathrm{c}}
\end{aligned}
$$

$P_{\mathrm{u} 1}$ and $P_{\mathrm{u} 2}-$ specific load for apartment buildings of the first and second group; 


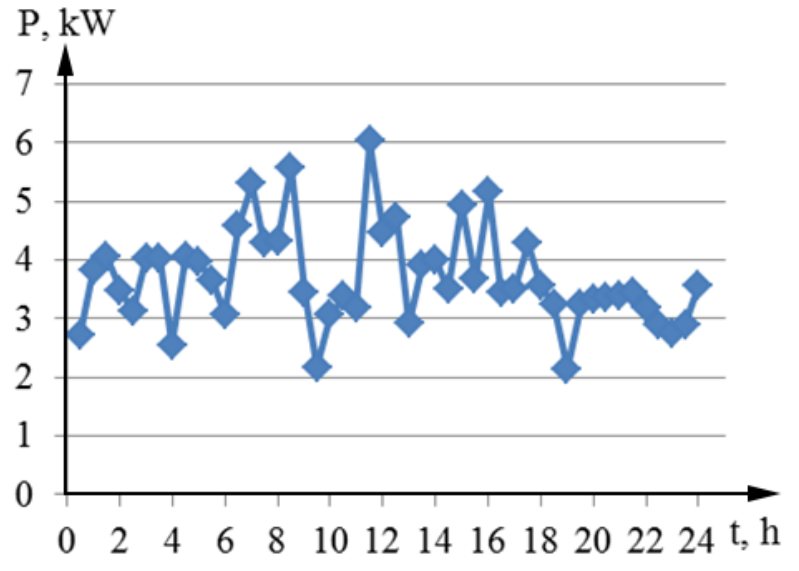

a)

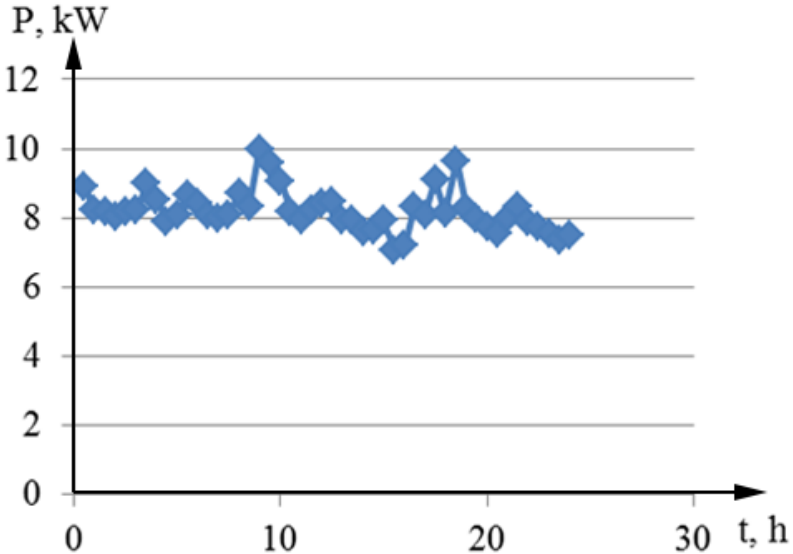

b)

Fig. 4. Daily power graphs for two cottages: $a$ - gas heating, $b$ - electric heating.
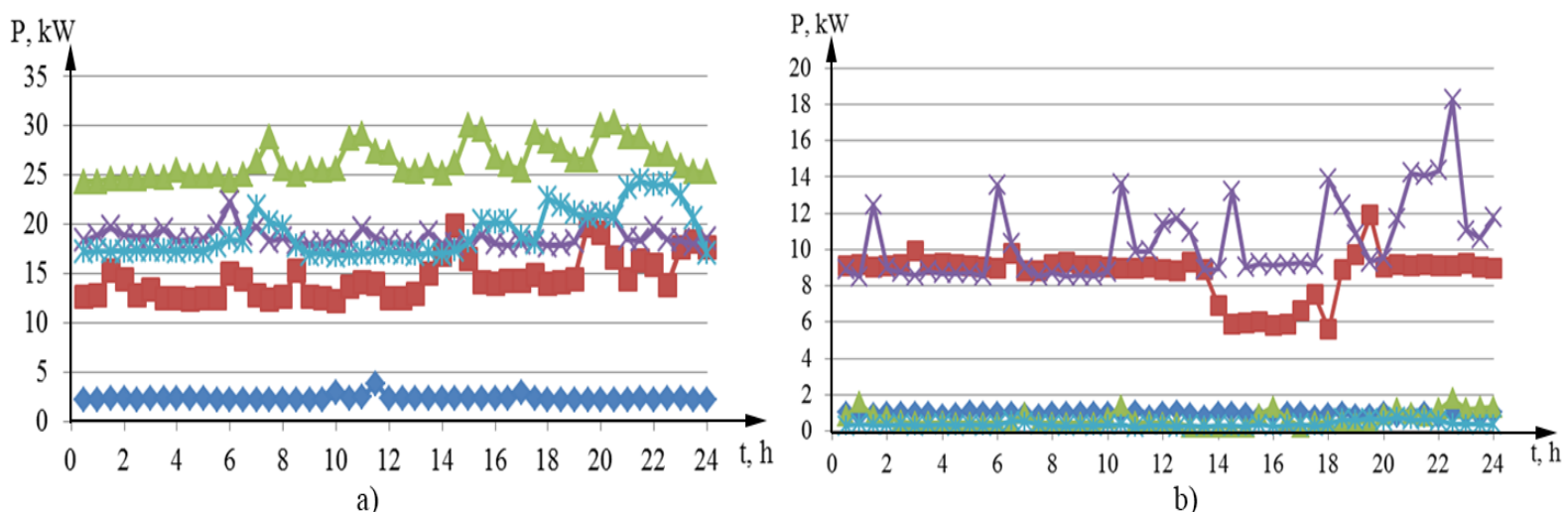

Fig. 5. Daily power profiles of rural cottages with partial use of electric boilers: $a$ - is a sample with maximum loads, b - is a sample with smaller loads.
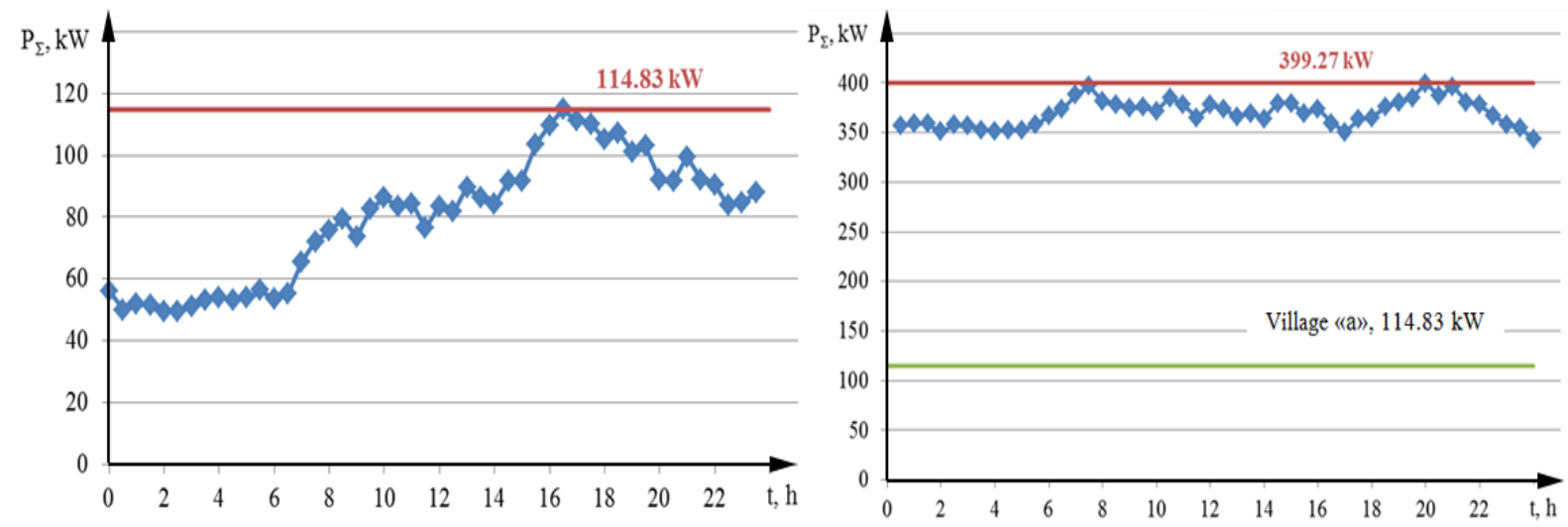

Fig. 6. The power profile of the total load of the village: a - village with gas heating, $b$ - a village with electric boilers.

$N$ ap1 and $N$ ap2 - total number of apartments in apartment buildings of the first and second group;

$k_{\mathrm{m}}$ - coefficient of simultaneity of the maximum load cottages and apartment buildings;

$P_{\mathrm{cl}}$ - power cottage main (first) group;

$P_{\mathrm{c} 2}$ - power cottage second group;

$P_{\mathrm{GS}}$ and $P_{\mathrm{Cf}}-$ total maximum power respectively, for a food store and cafe;
$k_{\mathrm{Kg}}$ and $k_{\mathrm{Sc}}-$ participation rates in maximum load for school and children's educational institutions;

$P_{\mathrm{Kg}}$ and $P_{\mathrm{Sc}}-$ maximum capacities, respectively, for school and children's educational institutions, where $P_{\mathrm{Kg}}$ $=p_{\mathrm{Kg}} N_{\mathrm{Kg}}, P_{\mathrm{Sc}}=p_{\mathrm{Sc}} N_{\mathrm{Sc}}$.

In turn, $p_{\mathrm{Kg}}, p_{\mathrm{Sc}}, N_{\mathrm{Kg}}, N_{\mathrm{Sc}}$ - respectively, the specific loads and the number of children in kindergarten and in school. 


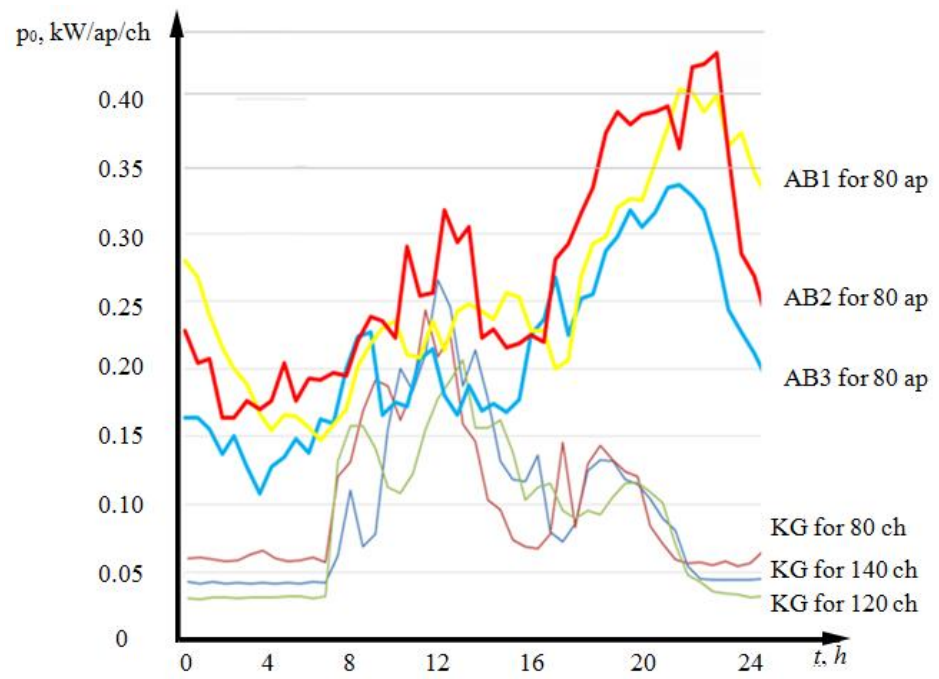

Fig. 7. Profiles of specific power apartment buildings and pre-school educational institution.

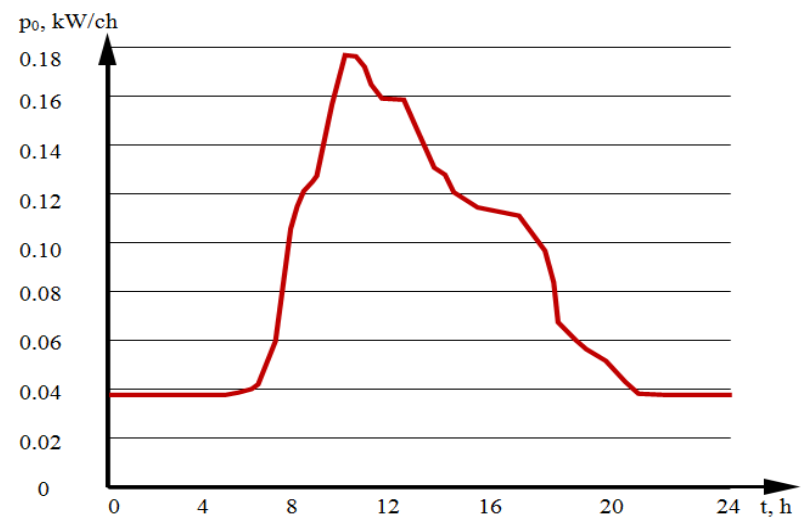

a)

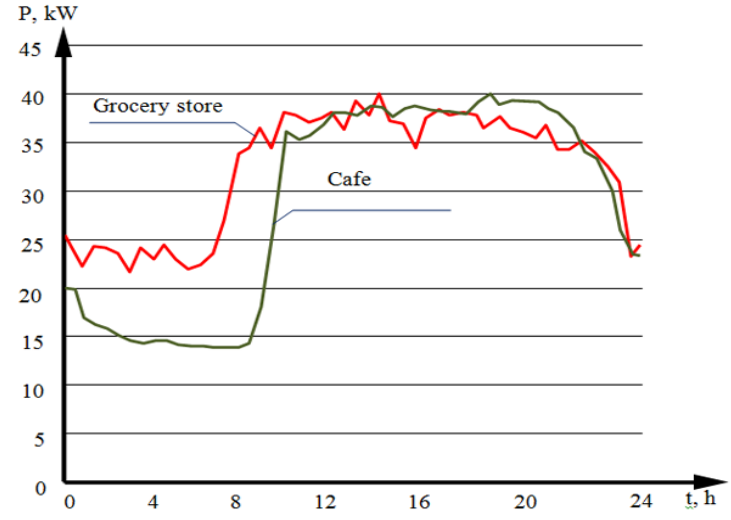

b)

Fig. 8. a - Daily profile of the specific power of the school for 270 students, b - Power profiles food store and cafe.

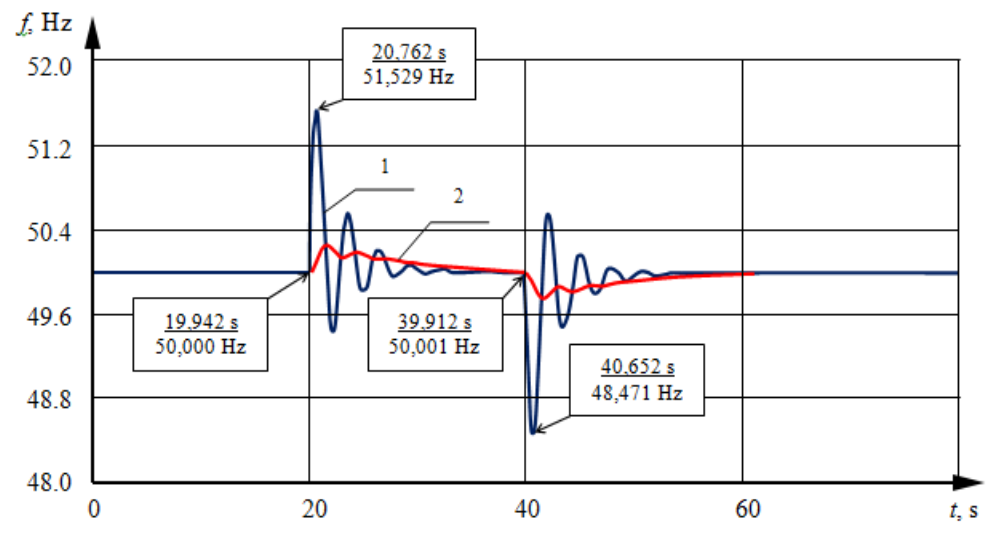

Fig. 9. Frequency deviation during discharge and load spikes: 1 - GPI without storage, 2 - GPI with a storage.

Based on the studies performed, the following values of specific loads can be recommended: $P_{\mathrm{u} 1}=0.53$ kW/apt.; $P_{\mathrm{u} 2}=0.61 \mathrm{~kW} /$ apt.; $P_{\mathrm{c} 1}=7.5 \mathrm{~kW} ; P_{\mathrm{c} 2}=25 \mathrm{~kW}$; $p_{\mathrm{Kg}}=2.2 \mathrm{~kW} /$ children(ch) (up to 55 places); $p_{\mathrm{Kg}}=1$ $\mathrm{kW} / \mathrm{ch}$ (more than 55 places and up to 110 places); $p_{\mathrm{Sc}}=$ $1 \mathrm{~kW} / \mathrm{ch}$ (up to 300 children); $k_{\mathrm{Kg}}=0.7$ and $k_{\mathrm{Sc}}=0.6$.

Formula (1) is used to select the rated power of autonomous power installations. In the absence of energy storages, given the social importance of uninterrupted decentralized power supply in the northern territories, it is necessary to use at least two independent power sources. Then the rated power of each satisfies the condition:

$$
P_{\text {nom }}>P_{\max } / 2 \text {. }
$$


Table 2. Cost indicators storages.

\begin{tabular}{|c|c|c|c|c|}
\hline View & Type & $\mathbf{P}=\mathbf{1}$ MW & $\mathbf{P}=\mathbf{5} \mathbf{M W}$ & $\mathbf{P}=\mathbf{1 0}$ MW \\
\hline & Battery & Ubat $=470 \mathrm{~V}$ & Ubat $=2352 \mathrm{~V}$ & Ubat $=4700 \mathrm{~V}$ \\
& LT-LFP 700P & $\mathrm{C}=700 \mathrm{Ah}$ & $\mathrm{C}=700 \mathrm{Ah}$ & $\mathrm{C}=700 \mathrm{Ah}$ \\
& $\mathrm{W}=329 \mathrm{kWh}$ & $\mathrm{W}=1645 \mathrm{kWh}$ & $\mathrm{W}=3290 \mathrm{kWh}$ \\
& & $\mathrm{N}=147$ & $\mathrm{~N}=735$ & $\mathrm{~N}=1469$ \\
& & 7.2 million rubles & 36.01 million rubles & 71.9 million rubles \\
\hline & Supercapacitor & $\mathrm{U}_{\mathrm{SC}}=526 \mathrm{~V}$ & $\mathrm{U}_{\mathrm{SC}}=2632 \mathrm{~V}$ & $\mathrm{U}_{\mathrm{SC}}=5263 \mathrm{~V}$ \\
& $\mathrm{C}=94 \mathrm{~F}$ & $\mathrm{C}=94 \mathrm{~F}$ & $\mathrm{C}=94 \mathrm{~F}$ \\
& $\mathrm{~W}=5 \mathrm{MJ}$ & $\mathrm{W}=25 \mathrm{MJ}$ & $\mathrm{W}=50 \mathrm{MJ}$ \\
& $\mathrm{N}=19$ & $\mathrm{~N}=95$ & $\mathrm{~N}=189$ \\
& & 3.9 million rubles & 19.7 million rubles & 39.4 million rubles \\
\hline
\end{tabular}

When using the GPI as a power source, the emergency shutdown of one of them will lead to a shutdown and the second due to a sudden load rise. Figure 9 shows a diagram of the variation of the frequency of electric current with a step load change within the limits of permissible values for one of the Caterpillar GPI.

According to the ISO 8528-5 standard, for the class of generators $\mathrm{G} 3$, the frequency range is allowed during rises and load dumps within $+10 /-15 \%$ (frequency recovery time $3 \mathrm{~s}$ ). At the same time, already at idle speed of the GPI operation, the allowable load increase does not exceed $15 \%$. It is obvious that the adoption of an emergency load when one of the two sources is disconnected will require the use of electrochemical storage. If you use the formula (2), then its power should be at least half the power of the entire load.

The optimal combination of the GPI and the drive is to increase the number of GPI. At the same time, the opportunities for their mutual redundancy in the autonomous power supply system increase and the required storage power is reduced [6-10].

Perform an approximate estimate of the economic effect [10-15]. So, if the load by the equation (1) is 2 MW, then you can install two GPI with an electric power of $2 * 2.0 \mathrm{MW}$ or four GPI with an electric power of $4 *$ 1.0 MW. In the first case, an electrochemical storage unit with an electric power of $2 \mathrm{MW}$ is required, in the second case - $1 \mathrm{MW}$. If the storage is used only to compensate for short-term power outages, then it suffices to use supercapacitors. In the first case with an electric power of $2 \mathrm{MW}$, in the second case $1 \mathrm{MW}$. Based on the duration of their work of 5 seconds, energy of $5 \mathrm{MJ}$, the cost of a $1 \mathrm{MW}$ storage will be 3.9 million rubles plus 2.6 million rubles on the device coordination with the grid (inverter and transformer). Total on the storage will be required in the second variant 5.5 million rubles and 11 million rubles in the first variant, table 2 .

In the case when the smoothing of the load graph is intended in order to save fuel, batteries are used as a storage. Consider them at the same electric power - 1 MW. Under the condition of their work for issuing a $0.25 \mathrm{MW}$ operating mode for 1 hour, the daily cost of a 1 MW storage will be 7 million rubles. We take into account that in the mode of short-term battery discharge, it is permissible to work with an increased current, which for most batteries is $5 \mathrm{C}$. This means that the rated power of the battery can be reduced to $250-300 \mathrm{~kW}$ and the price will be about 3 million rubles. In this case, in normal mode, the battery serves to smooth the load pattern.

Load dump from the operating power installations when the source is turned back on occurs rather slowly, with a predetermined set speed of the power installation turned on

\section{Conclusions}

Electrical loads of residential low-rise settlements and urban apartment buildings differ by $2-3$ times from their calculated values given by regulatory documents. For children's and school educational institutions, design loads also give values of maximum power that are 1,5 to 2 times overestimated. The choice of power installations in autonomous power supply systems in these cases according to design data leads to a significant overestimation of their installed electric power.

The load rises and dumps, which take place in the operation of an apartment and public buildings, are relatively small and are smoothed out when they are summed up in the busbar sections of the switchgear. Thus, the inclusion of boilers in children's educational institutions leads to an almost instantaneous increase in power by $20-40 \mathrm{~kW}$, and the inclusion of a fire alarm emergency exhaust ventilation - up to $100 \mathrm{~kW}$. The greatest danger to the GPI is the emergency shutdown of one of the generation sources. For the successful application of GPI operating on associated petroleum gas, the stabilization of the frequency in an electrical AC grid can be achieved by installing electrochemical batteries on the corresponding currents of relatively low electrical intensity. At the same time, issues of fuel economy for them become secondary.

The use of associated petroleum gas in remote areas, for which the cost of imported liquid fuel increases many times and with its transport capacities creates an additional environmental burden, when using storage devices, it has no alternative.

\section{Acknowledgments}

Research is made with financial support of the Ministry of Education and Science of the Russian Federation 
within implementation of the federal special program «Research and development in the priority directions of scientific and technological complex of Russia for 20142020», the agreement on granting a subsidy № 075-022018-190-1 stage, unique identifier of applied scientific research (project) RFMEFI57418X0188All research articles should have a funding acknowledgment statement included

\section{References}

1. A.E. Veselov, Development of a new structure for electricity distribution networks of 6 and $10 \mathrm{kV}$ industrial power supply systems, Vestnik of Kolskogo center of the Russian Academy of Sciences, 4 (2015)

2. N.I. Voropai, Distributed generation in power systems, Int. Scientific and Practical Conf. Small Energy-2005http:/www.combienergy.ru/stat/983Raspredelennaya-generaciya

3. K.R. Bakhteev, The Improving quality of power supply to industrial consumers using high-power energy storage, IEEE 59th Int Scientific Conf. on Power and Electrical Engineering of Riga Technical University,

DOI:10.1109/RTUCON.2018.8659834, 1-5 (2018)

4. J. Seymour, The Seven Types of Power Problems, White Paper, 1 (2018) https://www.apc.com/salestools/VAVR-5WKLK

5. A set of Rules SP 256.1325800.2016 2016 Electrical installations of the apartment and public buildings Rules of projecting and installation Order of the Ministry of Construction of Russia (Moscow)

6. A. Fedotov, Application of local Fourier transform to a mathematical simulation of synchronous machines with valve excitation systems, Latvian Journal of Physics and Technical Sciences, 54(1), 31-40 (2017)

7. A. Fedotov, Influence of the small distributed generation on the level of residual voltage at short circuits, Proc. of higher educational institutions Energy problems Issue, 3-4, 45-49 (2016)

8. K. Bakhteev, The improving efficiency of electric receivers on the industrial enterprises in case of short-term power outages Proc, 20th Int. Scientific Conf. on Electric Power Engineering, 347-352 (2019)

9. K.R. Bakhteev, Creation of a big power hybrid electric energy storage for prevention short-term interruption of power supply to industrial consumers Proc, of higher educational institutions Energy problems, 20(3-4), 36-44 (2018) doi.org/10.30724/1998-9903-2018-20-3-4-36-44

10. O. Abramova, Supercapacitor and Battery Comparison (2016) https://bestenergy.com.ua/support/battery/bu-209)

11. E.V. Kryukov, Application thyristor booster devices for improving the quality of electric power systems, Dissertation for the degree of Ph.D. (2018)
12. Lithium-ion battery manufacturers Official site of Litotech http://www.liotech.ru/liamanufacturers

13. L. Benjamin, Battery Demonstration at American Electric Power A Study for the DOE Energy Storage Program, Sandia report SAND2006-6740, 55 (2007)

14. C. Curry, Lithium-ion battery Costs and Market, Bloomberg New Energy Finance, squeezed margins seek technology improvements \& new business models (2017)

15. R.N. Berdnikov, Hybrid electricity storage for the UNEG on the basis of batteries and supercapacitors, Energy of the Unified Network, 1 (2013) 